\title{
SUPPORTING SENSEMAKING TO DEAL WITH ORGANIZATIONAL COMPLEXITY
}

\author{
S. JANTUNEN \\ Lappeenranta University of Technology, Finland.
}

\begin{abstract}
Many organizations have in recent years experienced increased inadequacy of their management practices to deal with their complex and turbulent work-related challenges. Failing to recognize the complexity in their problems, organizations have persisted in applying inappropriate methods and tools to them. When the workrelated problems are ambiguous, complex, and constrained, business processes tuned for decision-making have begun to degrade providing a false sense of security based on unjustified numerical certainty. Examining these challenges in the light of complexity theory could potentially help organizations to deal with their challenges in a more effective way. For understanding complex and ambiguous issues, people must interact, discuss, and share their different perspectives and interpretations. Existing literature recognizes sensemaking as one way for group members to understand and talk about complexity. Unfortunately, little has yet been reported on exactly how the properties of sensemaking can be materialized in practice. This paper discusses sensemaking as a potential framework to deal with complexity. The paper (1) describes on a practical level interventions taken in one case company to support sensemaking, (2) illustrates the creation of different plausible interpretations of what essentially describes the case company's current environment, (3) describes how the creation of shared understanding is currently being shaped into a commitment towards action, and (4) reflects the findings and experiences with the existing knowledge on complexity and sensemaking.

Keywords: business processes, complexity, sensemaking.
\end{abstract}

\section{INTRODUCTION}

During the recent years, we have witnessed rapid development of information technology resulting with increased interconnectedness, transparency, empowerment of individuals, speed of transactions, and decreased cost of information [1]. These are all trends that are likely to introduce complexity to the way organizations manage their businesses. Advances in technology have led many firms to the point that innovations cannot be accomplished any more by individuals acting independently [2,3]. Furthermore, continuously deepening globalization has forced firms to find their competitive advantage from their flexibility, agility, capability to innovate, and ability to understand the customer needs [4]. Consequently, firms have been driven to a situation in which they need to be able to collaborate effectively with other firms, whether suppliers, customers, or competitors, and with other non-commercial knowledge-generating organizations.

When the business contexts have turned out to be ambiguous, complex, and constrained, processes tuned for decision-making have begun to degrade providing a false sense of security based on unjustified numerical certainty. Failing to recognize the complex and turbulent dynamics in problems at hand, firms persist in applying inappropriate methods and tools to them [5]. Examining the work-related challenges in the light of complexity theory could potentially help organizations to deal with their challenges in a more effective way [6].

For understanding complex and ambiguous issues, people must interact, discuss, and share their different perspectives and interpretations. Existing literature recognizes sensemaking [7] as one way for group members to understand and talk about complexity [8]. Unfortunately, little has yet been reported on exactly how the properties of sensemaking can be materialized in practice. 
This paper discusses sensemaking as a potential framework to deal with complexity. The paper (1) describes on a practical-level interventions taken in one case company to support sensemaking, (2) illustrates the creation of different plausible interpretations of what essentially describes the case company's current environment, (3) describes how the creation of shared understanding is currently being shaped into a commitment towards action, and (4) reflects the findings and experiences with the existing knowledge of complexity and sensemaking.

The remainder of this paper is organized as follows. Section 2 introduces the framework of sensemaking in greater detail, Section 3 describes the empirical context including the case company and the research project. Section 4 describes the research methodology, data gathering, and empirical results. Section 5 discusses the findings and reflects the experiences to the literature of complexity and sensemaking. Finally, Section 6 concludes the paper.

\section{SENSEMAKING}

Sensemaking, a framework proposed by Weick [7], seeks to explain how people structure unknown so as to be able to act in it. Sensemaking enables us to turn the ongoing complexity of the world into 'a situation that is comprehended explicitly in words and that serves as a springboard into action' [9]. In more concrete terms, sensemaking involves (1) coming up with a plausible understanding - a map of a shifting world; (2) testing this map with others through data collection, action, and conversation; and then (3) refining, or abandoning, the map depending on how credible it is [10].

Sensemaking is an ongoing process that is triggered when the current state of the world is perceived to be different from the expected state of the world, or when there is no obvious way to engage the world [9]. At its most basic, sensemaking is about understanding how different meanings are assigned to the same event [11]. According to Weick [7], at least seven distinguishing characteristics set sensemaking apart from other explanatory processes such as understanding, interpretation, and attribution. Sensemaking can be understood as a process that is [7]:

1. Grounded in identity construction. The sensemaker is 'an ongoing puzzle undergoing continual redefinition, coincident with presenting some self to others and trying to decide which self is appropriate' [7, p. 20]. The definition of what is 'out there' depends on individual's perception of his or her identity. One's perception of identity also affects the actions one makes. Weick [7, p. 23] describes several points worth noting about identity. First, controlled, intentional sensemaking is triggered by a failure to confirm one's self. Second, sensemaking occurs in the service of maintaining a consistent, positive self-conception. Third, people learn about their identities by projecting them into an environment and observing the consequences. Fourth, people simultaneously try to shape and react to the environments they face. There is a complex mixture of proaction and reaction, and this complexity is commonplace in sensemaking. Fifth, the idea that sensemaking is self-referential suggests that self, rather than the environment, may be the text in need of interpretation.

2. Retrospective. The world people perceive is in reality a past world. However, whatever is occurring at the moment will influence what is discovered when people glance backward [7, p. 26]. Because events to be interpreted have already elapsed, anything that affects remembering will also affect the sense that is made of those memories. Elapsed experience appears to be equivocal, not because it makes no sense at all, but because it makes many different kinds of sense [7, p. 27]. The important point is that retrospective sensemaking is an activity in which many possible meanings may need to be synthesized. In such situation, what is important is clarity on values that indicate what is important in elapsed experience, which finally gives some sense of what that elapsed experience means [7, p. 28]. 
3. Enactive of sensible environments. People often produce part of the environment they face, while the environment partly defines who the people are. There is not some kind of monolithic, singular, fixed environment that exists detached from and external to people. Instead, the people are very much a part of their own environments. They act, and in doing so create the materials that become the constraints and opportunities they face [7, p. 31].

4. Social. Individual's thinking and social activities interact closely with each other. Sensemaking is never solitary because what a person does internally is contingent on others [7, p. 40]. One has to fit one's own line of activity in some manner to the action of others.

5. Ongoing. Sensemaking never starts or stops. People find themselves thrown into ongoing situations. To understand sensemaking is to be sensitive to the ways in which people chop moments out of continuous flows and extract cues from those moments [7, p. 43].

6. Focused on and by extracted cues. Extracted cues are simple, familiar structures that are seeds from which people develop a larger sense of what may be occurring [7, p. 50]. People in organizations are in different locations and are familiar with different domains, which mean that they have different interpretations of common events [7, p. 53].

7. Driven by plausibility rather than accuracy. Accuracy is meaningless when used to describe a filtered sense of the present, linked with a reconstruction of the past that has been edited in hindsight [7, p. 57]. Instead of accuracy, we need something that: (1) preserves plausibility and coherence, (2) is reasonable and memorable, (3) embodies past experience and expectations, (4) resonates with others, (5) can be constructed retrospectively but also can be used prospectively, (6) captures both feeling and though, (7) allows for embellishment to fit current oddities, and (8) is fun to construct. In short, what is necessary in sensemaking is a good story [7, p. 60].

\section{THE CASE COMPANY AND THE RESEARCH PROJECT}

Although sensemaking has been found to be a potential way to deal with complexity, little has yet been written how the seven properties of sensemaking [7] (Section 2) can be materialized in practice. Furthermore, little empirical reports exist describing experiences of conducting sensemaking activities within organizations. This paper seeks to contribute to these topics by describing empirical work within one case company. This section describes the case company in greater detail, along with the research project within which the empirical activities have been conducted.

Suomen Pienyrittäjäin Mainostoimisto (SPYM) is an advertisement company that offers services for business development, website design/development, graphical design, media advertising, digital marketing, communication, and content creation. SPYM was founded in 2008 in Jyväskylä, Finland. The company started their business by offering advertisement services to small businesses. Since its establishment, SPYM has systematically expanded its business. Today, SPYM employs 14 persons in the cities of Jyväskylä and Helsinki. In addition, SPYM utilizes several sub-contractors for a wide range of activities. In recent years, SPYM has started to serve increasingly larger customers while still serving the small businesses. This seems to have started to introduce new sources of complexity to the way SPYM operates. Larger customers seem to expect more disciplined collaboration compared to the small businesses who prefer hands on attitude and quick responses. Balancing between planned and ad hoc modes of working appears to have led to confusion, inefficiency, and eventually exhaustion of SPYM's employees. It has become evident that SPYM needs to find new ways of working in order to be able to cope with new sources of complexity in their business environment.

The necessity to find new ways of working has been the primary motivation for SPYM to join a recently established Organization 2.0 research project. The project, funded by the Finnish Funding Agency for Innovation (TEKES), is planned to be conducted from August 1, 2013 to December 31, 2015 in close collaboration with industrial partners by researchers originating from three Finnish 
research institutions: JAMK University of Applied Sciences, Lappeenranta University of Technology, and VTT Technical Research Centre of Finland. The Organization 2.0 project seeks to understand better what kinds of management practices would enhance firm's capabilities to cope with constant complexity and change (Research question 1) and how the novel management practices affect employees' job satisfaction and meaningfulness of work (Research question 2). To this end, research is conducted in two distinct work packages. The first work package identifies and investigates organizations that have developed novel and alternative ways to deal with their work related challenges. This work package seeks to (1) identify management practices that have proved to be effective and (2) explain the success of these practices by reflecting the findings with scientific knowledge. The research collaboration with SPYM is part of the second work package, which seeks to (1) develop novel management practices on the basis of scientific knowledge and (2) experiment and evaluate their effectiveness in real-life contexts.

\section{RESEARCH METHOD AND RESULTS}

The study in SPYM has followed action research methodology, which has been found to provide a valid methodological approach to the study of complexity [12]. Although action research is commonly credited to be originated by the work of social psychologist Kurt Lewin in the first half of the twentieth century, it is important to be aware that the methodology has since then evolved rather independently in different disciplines. Considering the history of action research, it is not surprising that there are now many different definitions and approaches for it [13]. Being aware of these differences is important, because different action research approaches have differing philosophical underpinnings and should hence be conducted and evaluated according with different criteria [14,15].

Our action research approach at SPYM resembles emancipatory action research that has its philosophical roots in critical theory. This form of action research seeks to 'assist practitioners in identifying and making explicit fundamental problems by first raising their collective consciousness' [16]. Newton and Burgess [15] have suggested that emancipatory action research should primarily be evaluated in terms of what Anderson and Herr [14] refer as the democratic and catalytic validities. Democratic validity is concerned with 'the extent to which research is done in collaboration with all parties who have a stake in the problem under investigation' [14]. Catalytic validity refers to the degree to which the research process have energized participants toward knowing reality in order to transform it [14].

Our attempt to conduct emancipatory action research has resulted with interventions, which have been designed to encourage the relevant stakeholders to understand their problematic situation themselves. In reality, these interventions have taken the form of workshops that have been organized at the premises of the case company. An overview of the workshops that have been organized to this point is presented in Table 1.

The first workshop was organized in May 15, 2014, with the objective to explore the context that SPYM is currently operating. To this end, three of SPYM's key persons including Managing Director, Production Manager, and Graphical Designer were first asked to brainstorm (1) things that they considered good in their current operating environment and then (2) things that they would wish to see improved. The brainstorming was conducted electronically by using a freely available software service, padlet.com. In practice, the participants used their personal laptops to input their ideas into a shared worksheet that displayed all ideas real time. These activities resulted with two separate worksheets with 75 things that were considered good in SPYM's current work environment, and 60 things that were wished to be improved in the current work environment. After the brainstorming session, the participants were asked to select 10 most significant things that they consider good in 
Table 1: Organized workshops, participants, and gathered data.

Workshop 1: Exploration of current situation (May 15, 2014)

Participants: (1) Managing Director, (2) Production Manager, (3) Graphical Designer

- 75 identified things that are considered good in the current work environment

- 60 identified things that a participant would wish to see improved in their work environment

- Participant-specific views of ten most essential good things (in the order of significance with written justification for each selection)

- Participant-specific views of 10 most significant things that need improvement (in the order of significance with written justification for each selection)

- Recorded discussions (54 min)

Workshop 2: Understanding how salient issues are related to each other (October 7, 2014) Participants: (1) Managing Director, (2) Production Manager

- Individually identified and documented relationships between emerged salient themes

- Recorded discussions (60 min)

Workshop 3: Towards shared understanding and common goals (December 3, 2014) Participants: (1) Managing Director, (2) Production Manager

- Collectively developed understanding of current situation

- Collectively developed agreement of common goals

- Recorded discussions (45 min)

their work environment and 10 most significant things that they would wish to see improved. The participants were also asked to write down justifications for their selections. The participants were then asked to present their top 10 lists. These presentations were recorded.

After the workshop, the researcher exported all data from padlet.com to a spreadsheet application in such way that each of the participants' responses was represented as an individual text box. Each text box was also color-coded in order to illustrate which of the questions the response was answering to. Green text box represented things that were considered good. Red text box represented things that were wished to be improved. The analysis of gathered responses proceeded from here visually by dragging the textboxes so that similar responses were moved close to each other. This step of analysis resulted with an interpretation of gathered data, described as a map of textbox clusters with similar statements next to each other. Each of the clusters was then labeled with a name that resembled a theme that emerged from the gathered data. The emerged themes, translated from Finnish to English, are presented in Fig. 1.

The second workshop was organized in October 7, 2014. In this workshop, the emerged themes were presented and discussed. Both Managing Director and Production Manager were then given an A3 paper, similar with Fig. 1. The participants were asked to individually draw connections between the themes and describe how the themes are related with each other. The participants were then asked to present their work. These presentations were recorded.

Based on the gathered data from the second workshop, the researcher created two diagrams, each of which described individual views of how essential themes were related with each other. These diagrams were then further interpreted in order to create a simplified understanding of what could be the most salient themes to be improved and what kinds of actions could likely to facilitate such 


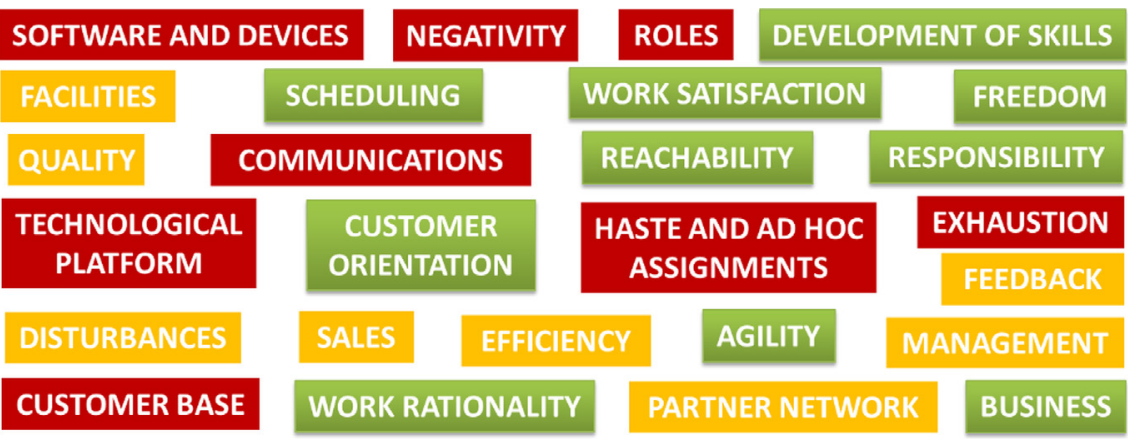

Figure 1: Essential themes that emerged from the first workshop. In themes displayed with green background, a majority of the brainstormed items contained things that were considered good. Themes displayed with yellow background contained equal amounts of items that were good and items that needed improvement. Themes displayed with red background contained largely things that needed improvement. The layout of the figure has been modified for the purposes of this paper.
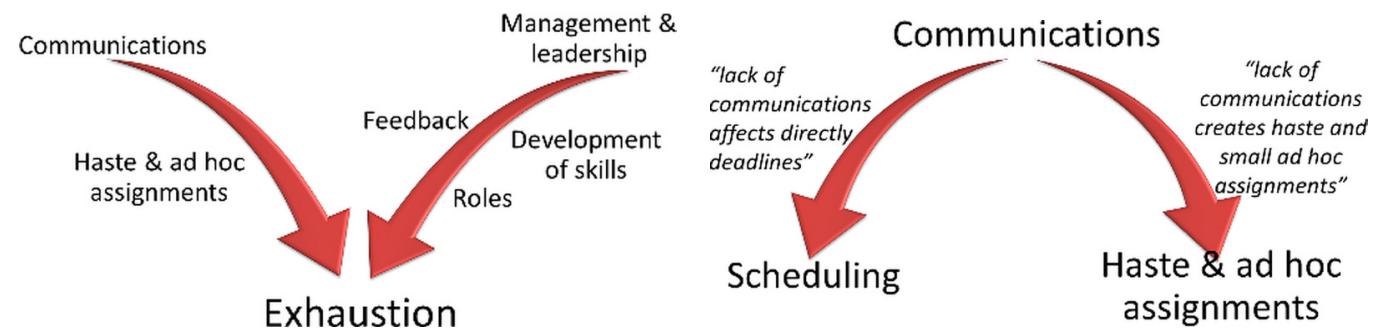

Figure 2: Two simplified interpretations derived from one individual view describing how emerged themes are related with each other.

improvement. An analysis of the first individual view resulted with two different simplified interpretations (Fig. 2). First of the interpretations argued that exhaustion of personnel can be managed: (1) by improving communications, which can help to minimize haste and ad hoc assignments and (2) through management and leadership practices by improving feedback mechanisms, clarification of roles, and development of skills. The second interpretation argued that the improvement in communications practices could enable improvements in scheduling and mitigate the challenges with haste and ad hoc assignments.

The analysis of the other individual view resulted with interpretation arguing that that the ultimate goal of the firm is profitability that can be defined in terms of quality and efficiency (Fig. 3). According to this interpretation, profitability is more likely to be reached if there are right kinds of conditions in terms of facilities, personnel, and work practices. In this interpretation, communication was seen as a key enabler for personnel to develop effective work practices to pursue for profitability.

At this point, the researcher also analyzed top 10 lists that were individually created in the first workshop. The results of this analysis highlighted the clear differences in individual thinking regarding what was considered good in SPYM's working environment and what was wished to be improved (Fig. 4).

All analysis results were presented and discussed in the third workshop on December 3, 2014. The purpose of this workshop was to come up with a shared view of SPYM's current working environment and to decide what will be the focus of forthcoming development activities. The presented 


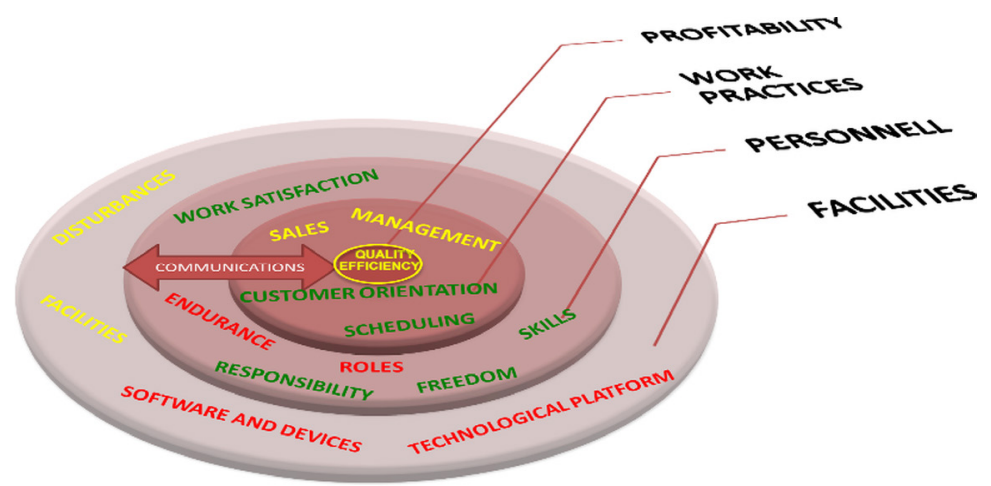

Figure 3: A simplified interpretation derived from the other individual view describing how emerged themes are related to each other.

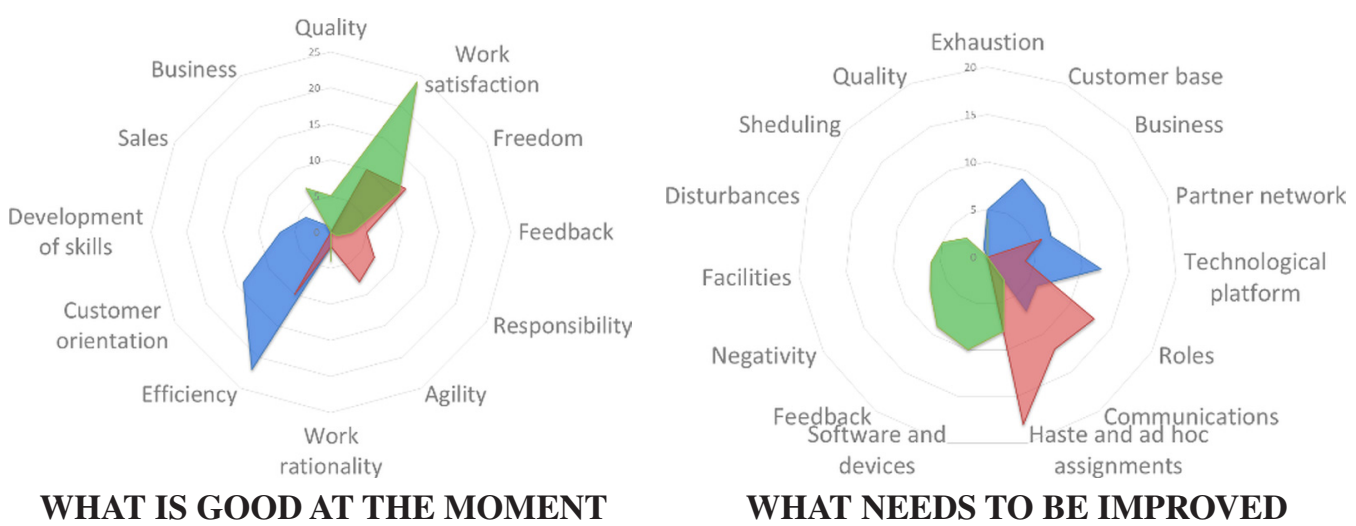

Figure 4: Analysis of personal views of what is good in the case company's working environment and what was wished to be improved.

research results (including Figs 1-4) met acceptance among the participants. These findings turned out to be well in line with the recent discussions of SPYM's management. Consequently, SPYM's management outlined in the workshop that, although profitability is the ultimate goal of the company, improvements in profitability are likely to be obtained by improving: (1) communications practices and (2) ways to clarify the roles of SPYM's personnel.

Now that communications and roles were selected as two primary themes to concentrate on, the focus of research collaboration started to shift from the development of shared understanding towards action. The management of SPYM agreed that a new workshop shall be organized in which all employees of SPYM shall participate. This workshop seeks to (1) further discuss and adjust the interpretation of SPYM's environment, (2) gain the acceptance and the involvement of SPYM's employees and (3) initiate the collective dialog for developing ways to improve communications and to clarify roles within SPYM.

\section{DISCUSSION}

A brief literature reveals that complexity thinking, sensemaking, and emancipatory action research all seek to explain and help us to understand the nature of reality so that we can deal with it in a more 
effective way. While complexity thinking argues that 'examination is merely a starting point and not a mapping, and that social systems need to be studied in their own right as complex social systems' [6], sensemaking viewpoint believes that 'sensemaking is not about truth and getting it right. Instead, it is about continued redrafting of an emerging story so that it becomes more comprehensive, incorporates more of the observed data, and is more resilient in the face of criticism' [9]. These kinds of arguments appear to be well aligned with the objective of emancipatory action research that seeks to 'increase the closeness between the actual problems encountered by practitioners in a specific setting and the kind of theory used to explain and resolve those problems' [16].

When we started to collaborate with SPYM, we adopted sensemaking as a theoretical framework to guide the design of the conducted workshops. Hence, in this section we reflect our interventions through the seven properties of sensemaking (Section 2). In our view, the analysis of participantspecific top 10 lists has illustrated how perceptions of stakeholders are clearly related to their professional identities (1. grounded in identity construction). Each participant had a distinct view of what was good in SPYM's work environment and what need to be improved. We have made an effort to make these differences in viewpoints explicit, so that the participants can reflect these findings against their past experience (2. retrospective) and investigate differing viewpoints in their own work environments (3. enactive of sensible environments). Throughout our collaboration with SPYM, we have encouraged for participatory approaches (4. social). We have also highlighted that our results are merely interpretations of current situation and that what is important is a change in attitude towards continuous adaptation (5. ongoing). Our interventions have been design to identify real issues in their work environment (6. focused on extracted cues) in order to build a more holistic explanation of what may be the story explaining these findings (7. driven by plausibility rather than accuracy).

\section{CONCLUSIONS}

This paper illustrated one way of supporting sensemaking in practice. Our reflection of the conducted activities within the case company suggests that sensemaking can be seen as one potential way of thinking to deal with complexity. The gathered feedback from the workshop participants also supports this argument. At the end of each workshop, we have asked the participants to share their thoughts of the conducted activities. These responses indicate that the participants have seen value in the process and potential in the forthcoming workshops.

What we did in the workshop was something that I could have personally addressed even for the whole day. That is, to think deeper about what is good in our working environments and how we could improve. I feel that what we achieved in this workshop was very a quickly accomplished picture about the essential themes of our working environment. That is, what is good about it and what needs to be improved. We also had a good discussion about these topics and learned from different perspectives. It is good to continue from here and think how we can develop our practices. This was interesting. Managing Director after the first workshop

I have recently spent quite a lot time to think about how to improve our efficiency and how to manage our sub-contractor network. Today, I have tried to take a different angle and think in terms of our daily routines. I was able to see quite quickly that communications is one of the essential issues to deal with in future. Production Manager after the first workshop

This was very interesting. I think we took just the right kind of step to the next level. Production Manager after the second workshop

It was nice to look at the documentation of the previous workshops and see how things have already changed since then. What I would wish from the future is an increased understanding 
of how to utilize our increased understanding when developing our working environment. It would be nice to know in greater detail what precisely needs to be improved and what we want to preserve. Managing Director after the third workshop

Now that the case company has created a shared understanding of what aspects of work shall be improved, our focus begin to shift towards supporting the development of practical ideas that implement the commonly shared goals.

\section{REFERENCES}

[1] Palmberg, K.,Complex adaptive systems as metaphors for organizational management, Learning Organization, 16(6), pp. 483-490, 2009. doi: http://dx.doi.org/10.1108/09696470910993954

[2] Coombs, R. \& Tetcalfe, J.S., Organizing for innovation: co-ordinating distributed innovation capabilities. Competence, Governance, and Entrepreneurship. Advances in Economic Strategy Research, eds. N. Foss, V. Mahnke, Oxford University Press: Oxford, pp. 209-231, 2000.

[3] Chesbrough, H., Open Innovation. The New Imperative for Creating and Profiting From Technology, Harvard Business School Press: Boston, MA, 2003.

[4] Alasoini, T., Mainettaan Parempi Työ, Taloustieto Oy: Helsinki, 2010.

[5] Conklin, J., Chapter 1: wicked problems \& social complexity. Dialogue Mapping: Building Shared Understanding of Wicked Problems, Chichester: West Sussex, England, 2005.

[6] Mitleton-Kelly, E., The principles of complexity and enabling infrastructures, Complex Systems and Evolutionary Perspectives on Organisations: The Application of Complexity Theory to Organisations, ed. E. Mitleton-Kelly, Elsevier Science Ltd: Oxford, UK, pp. 23-50, 2003.

[7] Weick, K.E., Sensemaking in Organizations, Sage Publications: Thousand Oaks, CA, pp. 23-50, 1995.

[8] Rutledge, M., Sensemaking as a tool in working with complexity, Organization Development Practitioner, 41(2), pp. 19-24, 2009.

[9] Weick, K.E., Sutcliffe, K.M. \& Obstfeld, D., Organizing and the process of sensemaking, Organization Science, 16(4), pp. 409-421, 2005. doi: http://dx.doi.org/10.1287/orsc.1050.0133

[10] Ancona, D., Sensemaking: framing and acting in the unknown. The Handbook for Teaching Leadership: Knowing, Doing, and Being, eds. S. Snook, N. Nohria, R. Khurana, Sage Publications Ltd: Thousand Oaks, CA, pp. 3-21, 2012.

[11] Mills, J.H., Thurlow, A. \& Mills, A.J., Making sense of sensemaking: the critical sensemaking approach. Qualitative Research in Organizations and Management: An International Journal, 5(2), pp. 182-195, 2010. doi: http://dx.doi.org/10.1108/17465641011068857

[12] Phelps, R., and Hase, S., Complexity and action research: exploring the theoretical and methodological connections. Educational Action Research, 10(3), pp. 507-524, 2002. doi: http://dx.doi.org/10.1080/09650790200200198

[13] Waterman, H., Tillen, D., Dickson, R. \& De Koning, K., Action research: a systematic review and guidance for assessment. Health Technology Assessment, 5(23), pp. 1-166, 2001. doi: http://dx.doi.org/10.3310/hta5230

[14] Anderson, G.L. \& Herr, K., The new paradigm wars: is there room for rigorous practitioner knowledge in schools and universities? Educational Researcher, 28(12), pp. 12-40, 1999. doi: http://dx.doi.org/10.3102/0013189x028005012

[15] Newton, P. \& Burgess, D., Exploring types of educational action research: implications for research validity, International Journal of Qualitative Methods, 7(4), pp. 18-30, 2008.

[16] Holter, I.M. \& Schwartz-Barcott, C., Action research: what is it? how has it been used and how can it be used in nursing? Journal of Advanced Nursing, 18(2), pp. 298-304, 1993. doi: http:// dx.doi.org/10.1046/j.1365-2648.1993.18020298.x 